\title{
Early modern period adobe in Sicily: Recent finds
}

\author{
M.L. Germanà \\ Dipartimento di Architettura, Università di Palermo, Italy
}

\begin{abstract}
Earthen architecture in ancient Sicily can be linked to a technological continuity common to the whole Mediterranean basin. The island possesses numerous finds, dating back to periods ranging from pre-history to the Hellenistic-Roman age, during which adobe was a widespread technique. The archaeological field had been the only one investigated, also due to the fact that more recent evidence had shown that the use of earth as a principal element in wall-building was unknown in Sicily. Recently, traces of adobe have been discovered in the historical centre of Cefalù, on the northern coast of Sicily; these few scraps are to be found in residential buildings made primarily of stone. Albeit modest in quantity, these traces are important for our historical knowledge and to reinforce the hypothesis of contemporary earthen architecture in Sicily.
\end{abstract}

\section{INTRODUCTION}

Earth has been detected in buildings dating back to various epochs and in various geographical areas. Earth is a building material that is still pertinent at all latitudes, and has negligible environmental impact; one has only to think of its widespread availability and the consequent reduction in transportation, the extremely inconsequential amount of energy required for its transformation, the elimination of the need for disposal, recycling of waste and dumping. In the last decades great progress has been achieved in the contemporary use of earth in building, though not in Italy, where the material and (perhaps more) non-material values of the links with the contextual reality hinder the use of earth building techniques in ordinary situations. Compared with others Italian Regions, this is more evident in Sicily, where the typical immediacy of earth building techniques (deeply rooted in the physical and cultural identity of the productive context) has been lost, because of the lack of flourishing building traditions.

Any hypothesis for bringing earthen architecture into present-day utilization needs to connect to local roots, if we wish to elude dreamland; for this reason, in order to improve historical knowledge it is important to reinforce it.

\section{EARTHEN ARCHITECTURE IN ANCIENT SICILY}

A National Research Project financed in 2005 by MIUR (Scientific, experimental and tacit knowledge and conservation actions of Earth Archi- tectural Heritage in Southern Italy; Programme Earthen Architectural Heritage in Sicily: knowledge and conservation processes) provided the opportunity to define a less fragmentary framework for earthen architecture in ancient Sicily, a kind of constructed heritage technique that is almost extinct and certainly less well-known than the same building material employed in more exotic contexts (Germanà 2009; Mecca et al. 2011). Before these studies, we only possessed rather scanty and partial knowledge. Sicily was almost entirely missing from the mosaic of earthen architecture in Italy, although there have been numerous occasions for comparing notes and disseminating results, as a consequence of which knowledge about many other regional situations has been consolidated, following research-lines such as: typological and technological investigation; the study of present conditions and particular conditions of deterioration and pathology; analysis of the mechanical behaviour of walls; possible legal repercussions, for the salvaging of existing constructions and the building of new ones (Bertagnin 1999; Scudo \& Sabbadini 1997).

A brief text in 1999 outlined the state of the art regarding knowledge of the earthen heritage in Sicily: the well-known 4th cent. BC fortifications of Capo Soprano at Gela; some pani di terra (lit. cakes of earth) cemented together with lime and clay mortar, cropping up occasionally in Cefalù in 17 th/18th cent. religious buildings; a few observations regarding pietra e tayu (lit. stone and mud), emerging from the archive studies of Henri Bresc (Mungiguerra 1999). Now that local archaeologists from the Sicilian heritage offices (e.g. Sebastiano Tusa, Rosalba Panvini and Francesca Spatafora) 
have become involved in research, Sicily is being described as a privileged field of observation, with regard to the ancient employment of earth for building purposes. Numerous finds, dating back to periods ranging from the Mesolithic to the Hellenistic age and representing various building typologies (residential constructions; craftworks areas, fortifications, religious buildings and graves), show the extent to which earthen architecture was widespread in Sicily. In addition, protective interventions carried out in the last fifty years have provided further interest, demonstrating the peculiar problems of conservation of these finds; these are particularly delicate, because of the intrinsic inconsistency of the building material, which is only durable if subjected to maintenance and adequately protected from moisture (Germanà 2011).

In the earliest examples and in subsequent developments in Sicily, earth was used in a mixed technique, along with other raw materials, ranging from stone to vegetal; depending on their on-site availability, these were employed in accordance with a technological continuity, common to the whole Mediterranean basin, deeply rooted in the Mesopotamian, Egyptian and Minoan-Mycenaean cultures (Tusa 2011; Spatafora 2011).

When the island opened up its frontiers to nonindigenous migrations, (e.g. Phoenician-Punic and Hellenic), ancient Sicily adopted adobe, a common technique in the Mediterranean basin from the 7 th cent. BC onwards (de Chazelles 1995; de Chazelles 2011), of which many more examples, and betterpreserved ones, have come down to us.

The best-known example is certainly the fortification of Capo Soprano at Gela (a monumental structure - over 350 metres of walling - which was unknown until 1948 because it was covered by a layer of sand over 12 metres deep, and which has also attracted interest as a result of the particular conservation problems). The utilisation of earthen bricks is also evident in the buildings on the same site; for instance, the Emporio of Bosco Littorio, dated 6th BC, where almost three-metre high adobe walls remain standing (Panvini 2008). Other sites, such as, for example, San Cataldo, Eraclea Minoa (Fig. 1), Solunto, Mothia, Marsala, Kamarina prove that adobe was widely used all over the island until the Hellenistic-Roman period.

The widespread availability of stone in most of the region may have been a crucial factor in Sicily not utilising earth as a principal element in masonry techniques.

However there remains the question as to why there was a clean break with building technique such as adobe, which was also widely used all over the island until the Hellenistic-Roman period. This interrogative gathers strength from an observation from neighbouring Calabria, where the same tradition of earthen bricks in the archaeological field was subsequently carried on until the

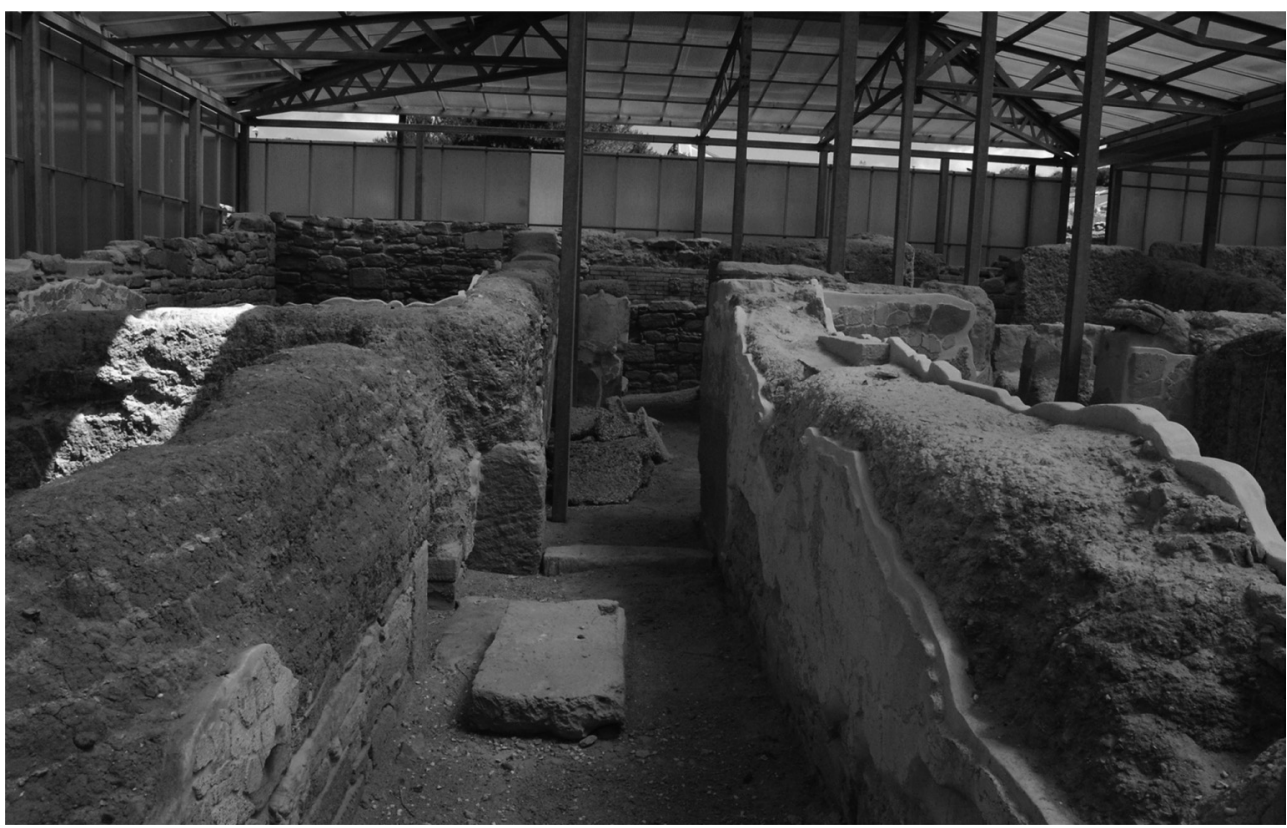

Figure 1. Eraclea Minoa (Agrigento). Domus, 2nd/1st century BC (photo by M.L. Germanà, 2013). 
last century, and to such an extent that it is still present in numerous relatively recent constructions (Cavalcanti \& Chimirri 1999). The scarcity of documented material evidence seems to prove that, during the medieval period and onwards, in Sicily, only in a few cases did walls continue to be built entirely from earth. The term tabia has been found in medieval archive sources, indicating walls built by a sort of rammed earth technique (Pezzini 2003). More well-known, and certainly more common in Sicily, were the masonry pietra e tayo (lit. stone and mud; rubble masonry) and a sacco (rubble masonry used as an infilling between cut stone walls). In these kind of masonry, earth was used not as a principal component, but in an integrating role for the stone elements (Germanà 2011b).

\section{RECENT FINDS OF EARTHEN BRICKS FROM THE EARLY MODERN AGE IN SICILY}

A document dated 1561 provides information that a potter who usually produced baked bricks, working in a mountain village in Palermo province, was obliged to supply forty thousand earthen bricks along with six thousand unfired bricks with straw (Fatta 2011). This somewhat isolated evidence could prove that earthen bricks were used in Sicily during the medieval and modern age as a low cost technique, and as an alternative, or in addition, to baked bricks or stone elements. This perception is now supported by direct evidence: new studies are providing knowledge about a sort of adobe technique found in buildings of the early modern age in Cefalù, on the northern coast of Sicily.

These advances have been possible thanks to several fortuitous and lucky circumstances and thanks to the collaboration of Fabio Vaccaro (Vaccaro 2012).

The first circumstance was hearing that the data regarding the pani di terra (Mungiguerra 1999) had in fact been provided by Pasquale Culotta, the well-known architect (also Dean of the Faculty of Architecture in Palermo), highly active in Cefalù until his sudden death in 2006. Thanks to his daughter Tania, photos were found in Culotta's archive, dated 1995, showing a wall that seems to be made of earthen bricks (Fig. 2). These finds are no longer visible, and it has not been possible to ascertain whether or not they still exist.

The second circumstance occurred in 2010, during works aimed at creating bed \& breakfast accommodation in an inconsequential building in the historical centre of Cefalù, when a wall in adobe was found by Mario Caliò and Monica Guercio, architects skilled in bio-architecture (Figs. 3-4). This wall stands in the second, and partly the third,

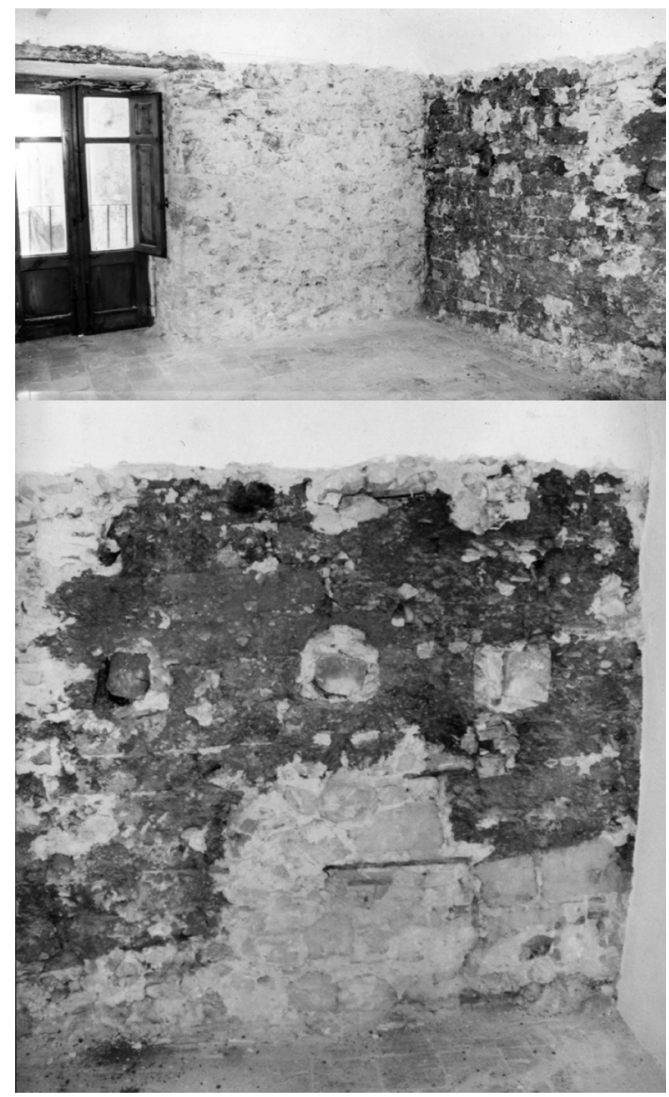

Figure 2. Inner wall in historical building in Cortile Rosariello, near S. Domenico (17th/18th cent. $\mathrm{AD})$ in Cefalù. Photos dated 1995, found in Archivio Culotta in 2012.

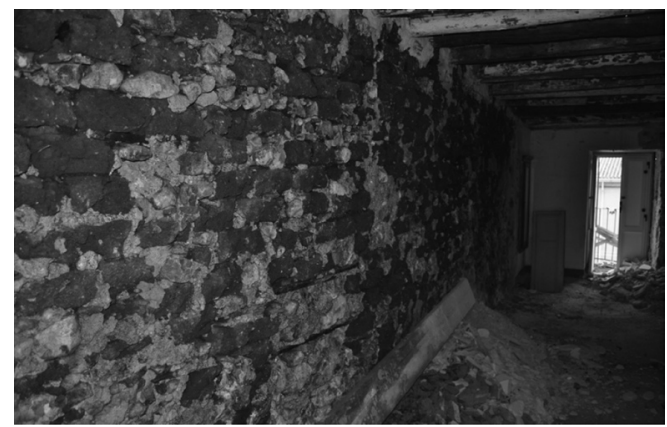

Figure 3. Wall in the second storey of a historical building in via Spinuzza in Cefalù (photo by M. Caliò \& M. Guercio, 2010).

of the three storeys of the building, which is made mainly in stone (Fig. 5). One might surmise that, in the absence of financial means, the adobe wall was built to meet the need for more space. 


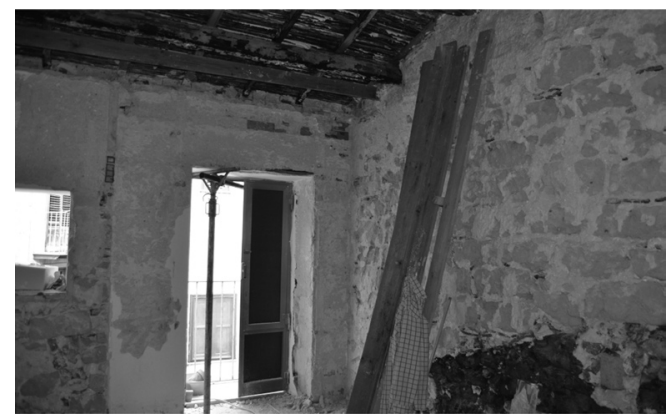

Figure 4. Third storey of a historical building in via Spinuzza a Cefalù; on the lower right, the wall in adobe (photo by M. Caliò \& M. Guercio, 2010).

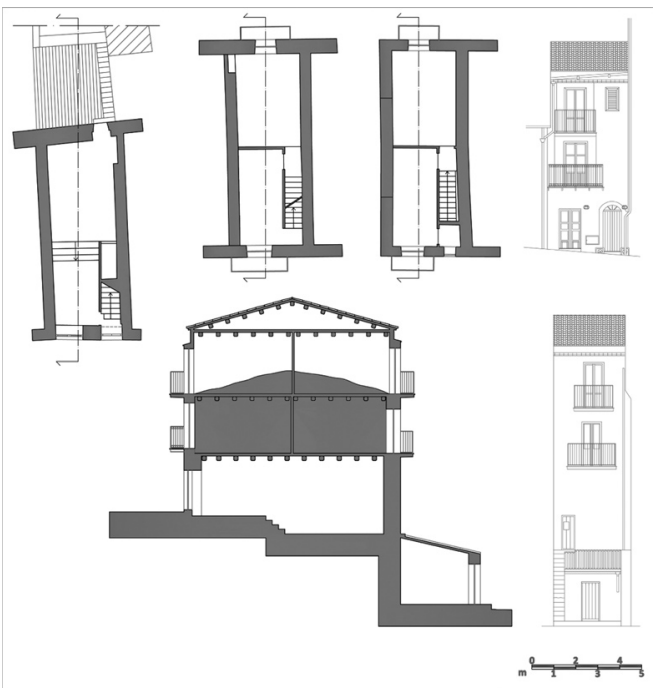

Figure 5. Building in via Spinuzza a Cefalù; in darker grey the wall in adobe in the second storey and in part of the third one (drawings by Fabio Vaccaro, 2012).

Now the adobe wall is covered by plaster, and only in two little recesses has it been left visible. In 2012 a sample was removed (Fig. 6), to examine the components of the mixture forming the bricks (whose dimensions are about $8 \times 18 \times 40 \mathrm{~cm}$ ). Preliminary analysis showed that slightly clayey earth was kneaded with sand and with heterogeneous aggregates: straw and terracotta fragments, bone splinters and slivers of wood, pieces of reed or little shells (Fig. 7). Radiocarbon dating carried out by CEDAD (CEntro DAtazione e Diagnostica, University of Salento) on the vegetable fibres contained in the sample, date this find to a period range most probably around $1640 \mathrm{AD}$.

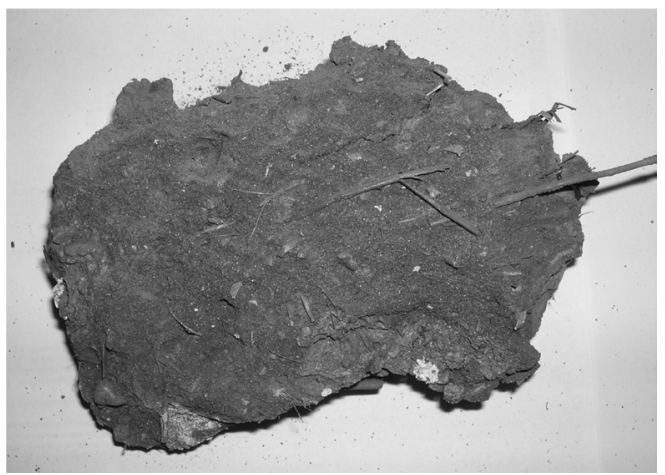

Figure 6. A piece of the sample of adobe extracted in via Spinuzza a Cefalù (photo by F. Vaccaro, 2012).

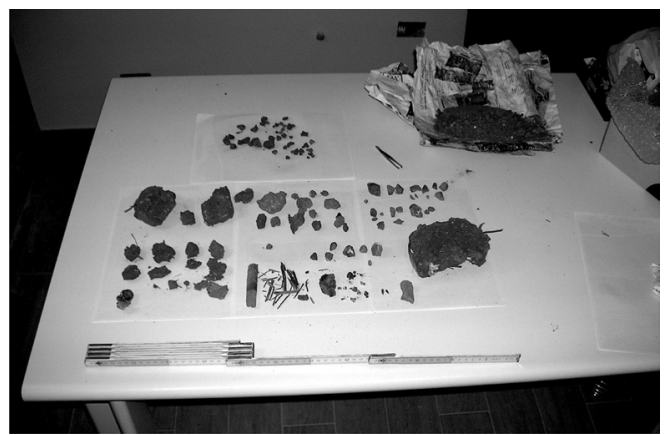

Figure 7. Aggregates found in the sample extracted in via Spinuzza a Cefalù (photo by F. Vaccaro, 2012).

The sample removed from via Spinuzza had a surprise in store: for nearly four centuries, the brick mixture had hidden a small head of a papier-maché Christ crucified (Fig. 8). This unexpected discovery was surprising because of its fortuity and there was consistency with radiocarbon dating. In fact, it is possible to link this find to one of the more evident effects of the Counter-Reformation, i.e. the accent placed on the educational purposes of Christian images and their consequent widespread diffusion among the lower social classes.

The conditions of the fragment and its combining with the brick mixture demonstrate that the Christ crucified had been added before drying. Apart from the underlying significance of salvation in the image (Caiazza 2007), this might suggest a sort of propitiatory custom in construction sites.

In 2013 Fabio Vaccaro found other traces of adobe in Cefalù, whilst browsing around, as was his wont, during works on historical buildings. These, along with the previously found traces, are in the same area of the town, which had flourished in the early modern age (Fig. 9); until now, only 

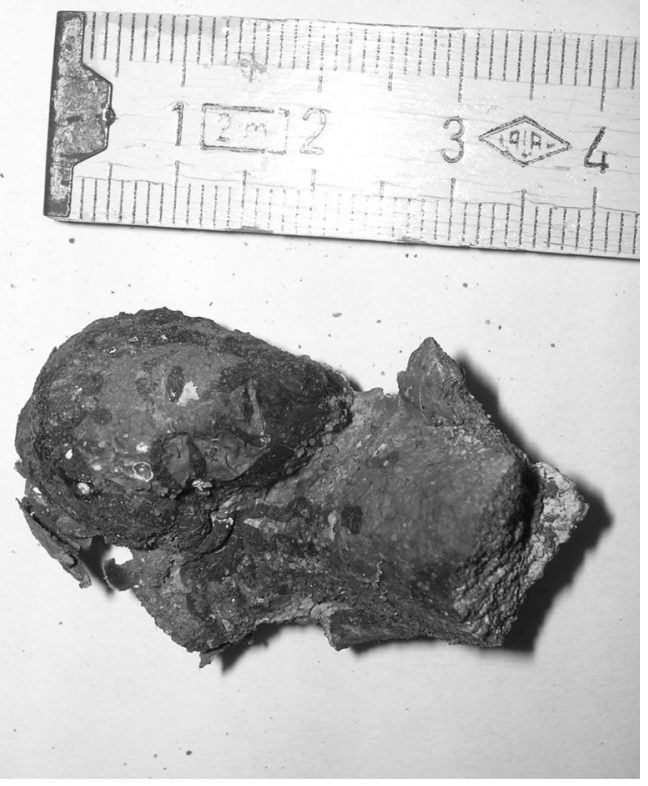

Figure 8. Crucified Christ papier-mache fragment found in the sample from via Spinuzza, Cefalù (photo by F. Vaccaro, 2012).

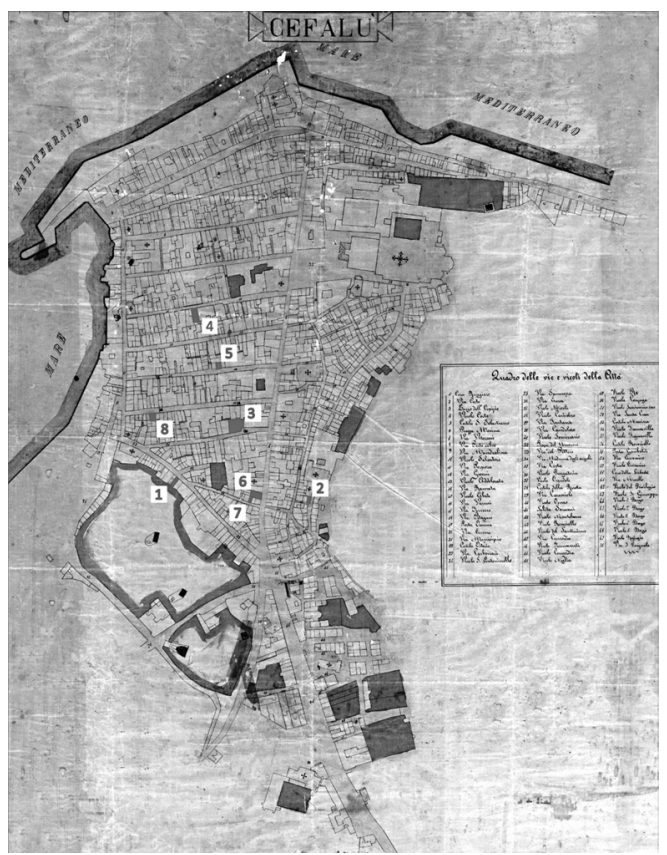

Figure 9. The town of Cefalù in a cadastral map dated $1850 / 60$, reporting the finds of adobe traces.

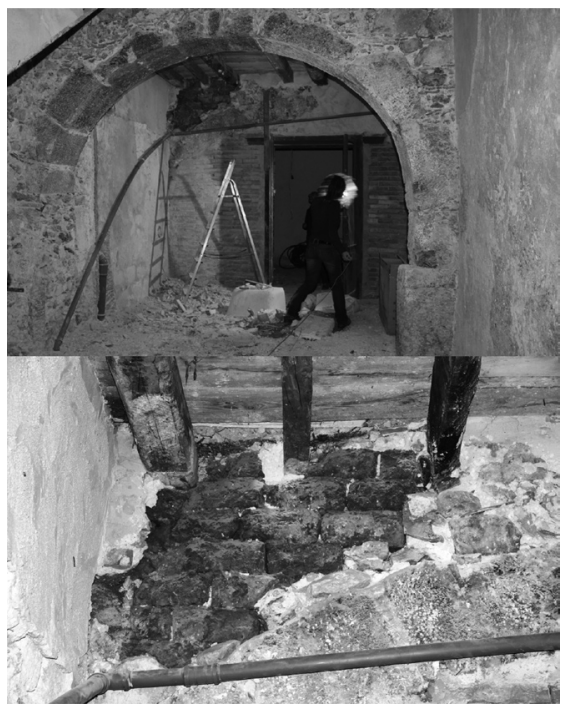

Figure 10. Filling made of earthen bricks over an arch, in a building in via Botta in Cefalù (photo by F. Vaccaro, 2013).

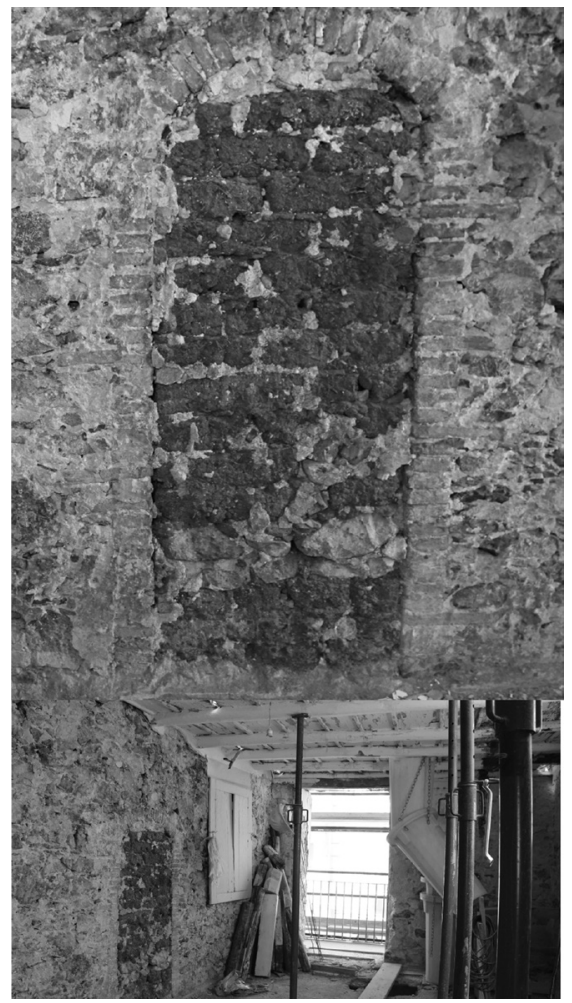

Figure 11. Empty in a stone-wall, filled-up by earth bricks, in a old building in via Vanni, Cefalù (photo by F. Vaccaro, 2013). 


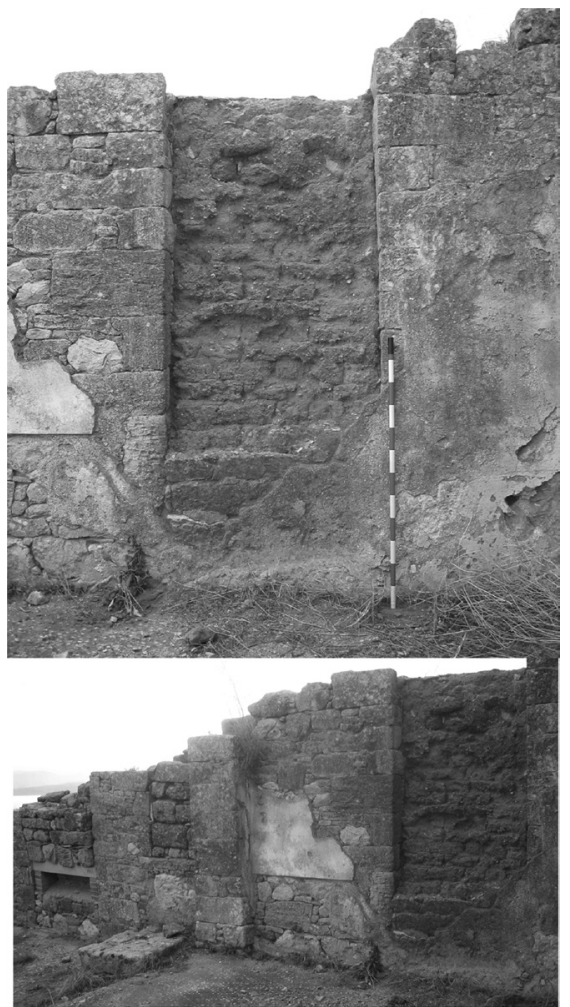

Figure 12. Solunto, Isolato 7 UA XIV. Casa a peristilio, I/II sec. BC (photo by M. Schiera, 2006).

little cavity fillers or completion of stone-walls have been found (Figs. 10-11).

\section{CONCLUSIONS}

By comparing the direct evidence of utilization of adobe in ancient Sicily with the recent finds described here (Figs. 11-12), it has been proved that this building technique (at the same time both remote and current) was used in Sicily for a period of over two millennia.

Albeit modest in amount and in quality, these traces are important for historical knowledge and to reinforce the hypothesis of contemporary earthen architecture in Sicily, thanks to the individuation of the necessary, specific, local roots.

\section{NOTES}

The contents of this paper were partially presented at the International Conference "Rencontres d'archéologie et d'histoire sur les constructions en terre crue", held in Pont du Gard (F) on 7-9 December 2012.

\section{REFERENCES}

Bertagnin, M. 1999. Architetture di terra in Italia. Tipologie, tecnologie e culture costruttive, Monfalcone (GO): Edicom.

Caiazza, G. 2007, E il Verbo si fece... Immagine. Dai simboli cruciformi ai crocifissi tridimensionali. Bollettino del Gruppo Archeologico Aquileiese (XVII): 3-17.

Cavalcanti O. \& Chimirri R. 1999. Di Fango, di Paglia... Architettura in terra cruda in Calabria. Soveria Mannelli (CZ): Rubbettino.

De Chazelles, C.A. 1995. Les origines de la construction en adobe en Extrême-Occident. Etudes Massaliètes (4): 49-58.

De Chazelles, C.A. 2011. La construction en brique crue moulée dans les pays de la Méditerranée, du Néolithique à l'époque romaine. In C.A. de Chazelles, A. Klein, N. Pousthomis (eds), Le cultures constructives de la brique crue: 153:164. Montpellier: Editions de L'Espérou.

Fatta, G. 2011. Earth in Sicilian wall: notes in progress. In Mecca et al. (eds): 291-299.

Germanà, M.L. 2009. Terra cruda nel patrimonio architettonico siciliano: conoscenza e conservazione. In M. Achenza, M. Correia, H. Guillaud (eds), Mediterra 2009, I Conferenza Mediterranea sull'architettura in terra cruda: 151-158. Monfalcone: Edicom.

Germanà, M.L. 2011a. Earth in ancient Sicilian architecture. In Mecca et al. (eds): 166-188.

Germanà, M.L. 2011b. A still to be explored heritage: stone and earthen architecture in Sicily. In Mecca et al. (eds): 280-290.

Mecca S., et al. (eds) 2011. Earth/Lands. Earthen Architecture of Southern Italy. Pisa: ETS.

Mungiguerra, C. 1999. Sicilia: dalle mura di Gela alla 'pietra e tayu'. In Bertagnin: 247-249.

Panvini, R. 2008. Strutture in mattoni crudi dell'antica Gela. In M.L. Germana \& R. Panvini (eds). La terra cruda nelle costruzioni: dalle testimonianze archeologiche all'ar-chitettura sostenibile. Palermo: Nuova Ipsa: 87-98.

Pezzini, E. 2003. Alcuni dati sull'uso della terra nell'architettura medievale a Palermo: fonti documentarie e testimonianze materiali. In Fiorillo R. \& Peduto P., (eds), 2003, Atti III Congresso Naz. di Archeologia medievale, Salerno 2-3/X/2003: 624-628.

Scudo G. \& Sabbadini S. (eds) 1997. Le regioni dell'architettura in terra in Italia. Rimini: Maggioli.

Spatafora, F. et al. 2011. The use of earth in central-western Sicily: attestations and documentary evidence. In Mecca et al. (eds): 201-225.

Tusa, S., 2011. Origins and initial developments of Sicilian earthen architecture in the Mediterranean context. In Mecca et al. (eds): 195-200.

Vaccaro, F. (2012), Cefalù in adobe: testimonianze in terra cruda report for the final exam of first degree course in Restauro, Recupero e Riqualificazione dell'Architettura at University of Palermo, supervisor M.L. Germanà. 